\title{
Brenner tumors of the ovary: clinical features and outcomes in a single-center cohort
}

\author{
(D) Dilek Yüksel ${ }^{1}$, (D) Çiğgdem Kılıç ${ }^{1}$, (D) Caner Çakır ${ }^{1}$, (D) Günsu Kimyon Cömert ${ }^{1}$, (D) Taner Turan¹, \\ (D) Eylem Ünlübilgin², (D) Nurettin Boran¹, (D) Fulya Kayıkçığlu1, (D) Sevgi Koç1 \\ ${ }^{1}$ Clinic of Gynecologic Oncology, University of Health Sciences Turkey, Etlik Zübeyde Hanım Women’s Health Teaching and \\ Research Hospital, Ankara, Turkey \\ ${ }^{2}$ Clinic of Gynecology and Obstetrics, University of Health Sciences Turkey, Etlik Zübeyde Hanım Women's Health Teaching \\ and Research Hospital, Ankara, Turkey
}

\section{Abstract}

Objective: The purpose of the present study was to evaluate the clinical and pathological features and oncological outcomes of Brenner tumors (BT).

Material and Methods: Evaluation was performed on the data of 46 patients with BTs retrieved from the oncology clinic database and pathology reports between 2005 and 2020.

Results: The median (range) age of the patients was 52 (22-75) years. Median (range) tumor size was 52.5 (5.0-300) mm. The tumor was benign in $37(80.4 \%)$, borderline in one (2.2\%), and malignant in the remaining eight (17.4\%). Ten (21.7\%) of the tumors were detected incidentally. Mixed tumor, BT plus another ovarian pathology, was found in 13 (28.2\%). Recurrence developed in 2/8 (25\%) with malignant BT (MBT). The stage of these patients was $3 \mathrm{C}$, and both received chemotherapy after surgery.

Conclusion: BTs are rare and generally detected incidentally. MBTs are treated in the same way as epithelial tumors. Due to the rarity of these tumors, lymphadenectomy and optimal chemotherapy regimens are controversial issues. (J Turk Ger Gynecol Assoc 2022; 23: 22-7)

Keywords: Brenner tumors of the ovary, malignant Brenner tumors, mixed tumors, rare tumors

Received: 01 January, 2021 Accepted: 13 September, 2021

\section{Introduction}

Ovarian Brenner tumors (BTs) are a rare type of epithelial ovarian tumor and constitute only $2-3 \%$ of all ovarian tumors (1). They were first described and named by Fritz Brenner in 1907 (2). BTs occur incidentally and frequently with other epithelial neoplasms (3). Incidental BTs are more common in oophorectomy specimens although, as the diagnosis is difficult, true incidence cannot be assessed (4).

The aim of this study was to report 46 cases with BTs of the ovary and to analyze the clinical and demographic features, and oncological outcomes.

\section{Material and Methods}

A retrospective evaluation was performed on patients with BT treated in our institution between 2005 and 2020. The clinical, surgical, and pathological data of the patients were collected from the gynecologic oncology department electronic database system, patient files, pathological reports, and operation notes. Data including age, menopausal status, tumoral features (tumor size, bilateral/unilateral), tumor markers (CA-125), surgical indications, type of surgical procedure, concomitant pathology, malignancy status, and follow-up information were obtained from the hospital registry. Written informed consent 
was obtained from all patients on admission for medical information to be used anonymously for academic purposes. Approval for the study was granted by the University of Health Sciences Turkey, Etlik Zübeyde Hanım Women's Health Care, Training and Research Hospital (approval number: 90057706799/8, date: 30.10.2019).

Patients with malignant BT (MBT) and BT accompanied by another gynecological malignancy were included in the study, and post-surgical follow-up was performed every three months for the first two years, every six months for the following three years, and annually for the subsequent five years. The 2014 International Federation of Gynecology and Obstetrics (FIGO) staging criteria were considered. For patients treated before 2014, cancer staging was re-assessed using the FIGO 2014 system from surgical and pathological reports.

Gynaecological examination, abdominal ultrasonography, and measurements of CA-125 levels were routinely performed at each follow-up visit. Patients with borderline pathology were followed-up annually.

\section{Statistical analysis}

Data obtained in the study were analyzed statistically using SPSS, version 17.0 software (SPSS Inc., Chicago, IL, USA). The demographic data of the patients and disease characteristics were evaluated with descriptive statistics, with continuous variables reported as median, minimum-maximum values, and categorical variables as number and percentage (\%).

\section{Results}

Evaluation was performed on 46 patients who presented during the study period. The patients had a median (range) age of 52 (22-75) years. The median (range) tumor size was 52.5 (5.0$300) \mathrm{mm}$. The median (range) preoperative CA-125 level was 19 (4.9-215) IU/mL.

Tumors were bilateral in $3(6.5 \%)$ patients, unilateral in the right ovary in 21 (45.7\%), and unilateral in the left ovary in 22 (47.8\%). Twenty-five (54.3\%) patients were postmenopausal. The tumor was benign in 37 patients (80.4\%), borderline in $1(2.2 \%)$ and malignant in 8 (17.4\%).

The most frequent features leading to diagnosis were adnexal mass $(71.7 \%)$, then myoma uteri (7\%), followed by abdominal pain, abnormal uterine bleeding, and prolapse.

Tumours were detected incidentally during surgery for other indications in $10(21.7 \%)$ cases. These were: cervical cancer $(n=2)$; ovarian cancer $(n=2)$; serous ovarian cancer $(n=1)$; endometrioid type of ovarian cancer $(n=1)$; myoma uteri $(n=3)$; prolapse $(n=1)$; high-grade cervical intraepithelial lesion $(n=1)$; and endometrial cancer $(n=1)$.

The patient with borderline BT accompanied by hyperplasia was found to have endometrial atypia, which was determined in preoperative endometrial biopsy and postoperative pathology. Mixed tumors consisting of BT and another ovarian pathology were detected in $13(28.2 \%)$ cases. Mucinous cystadenoma were concomitant in 7 (15.2\%) patients, serous cystadenoma in $2(4.3 \%)$, endometrioma in $2(4.3 \%)$, struma ovarii in 1 (2.1\%) and mature cystic teratoma in 1 (2.1\%). The clinical and pathological features of the patients are presented in Table 1.

The median age was 52 years (range, $36-57$ years) in cases with MBT and 52 years (range, 22-74 years) in benign cases.

Eight cases with MBT were examined separately in detail. Stage IIIC was identified in 4 patients, $1 \mathrm{~A}$ in 1 patient, IIA in 1 patient, IC1 in 1 patient, and IC3 in 1 patient. The median (range) follow-up time was 75 (36-75) months. In this period, recurrence was observed in $2 / 8$ (25\%). The patient with recurrence at stage $3 \mathrm{C}$, case no: 43 , underwent a total abdominal hysterectomy, bilateral salpingo-oophorectomy, bilateral pelvic lymph node dissection, appendectomy, and omentectomy, followed by six cycles of paclitaxel and carboplatin treatment, and had a recurrence in paraaortic + pelvic lymph node regions and the liver 86 months later. The other patient with recurrence (case no: 46) underwent a total abdominal hysterectomy, bilateral salpingo-oophorectomy, bilateral pelvic-paraaortic lymphadenectomy, and total omentectomy due to adnexal mass. After six cycles of chemotherapy (cisplatin + paclitaxel), the patient showed pulmonary + liver + pelvic recurrence in the $13^{\text {th }}$ month. The patient underwent bleomycin + etoposide + cisplatin chemotherapy and pelvic radiotherapy (RT), but died after 53 months due to progressive disease. The clinical and oncological characteristics of the cases with MBT are given in Table 2 . The recurrences were detected by imaging.

\section{Discussion}

Tumors originating from the surface epithelium of the ovary are the most common ovarian neoplasms. BTs are a rare subtype of epithelial ovarian tumors. The WHO categorizes BTs into three types - benign, borderline, and malignant. BTs are known as transitional cell tumors because of their histological similarity to the urothelium resembling epithelial components (5).

BTs usually present in the fifth to sixth decades of life. In a series of 13 cases reported by Gezginç et al. (6), 61.5\% of patients were post-menopausal and the median age was 55.6 years. Green et al. (7) also reported the mean age to be 58 years in 22 patients. Of the 46 patients in the current series, $54.3 \%$ were postmenopausal, and the median age was 52 years. The vast majority of reported cases of BT consist of small tumors and are detected incidentally when oophorectomy is performed for some other indication. In these cases tumor size is small, usually $<2 \mathrm{~cm}$ and most patients are asymptomatic (4). 
Table 1. The Clinical and pathological features of the patients

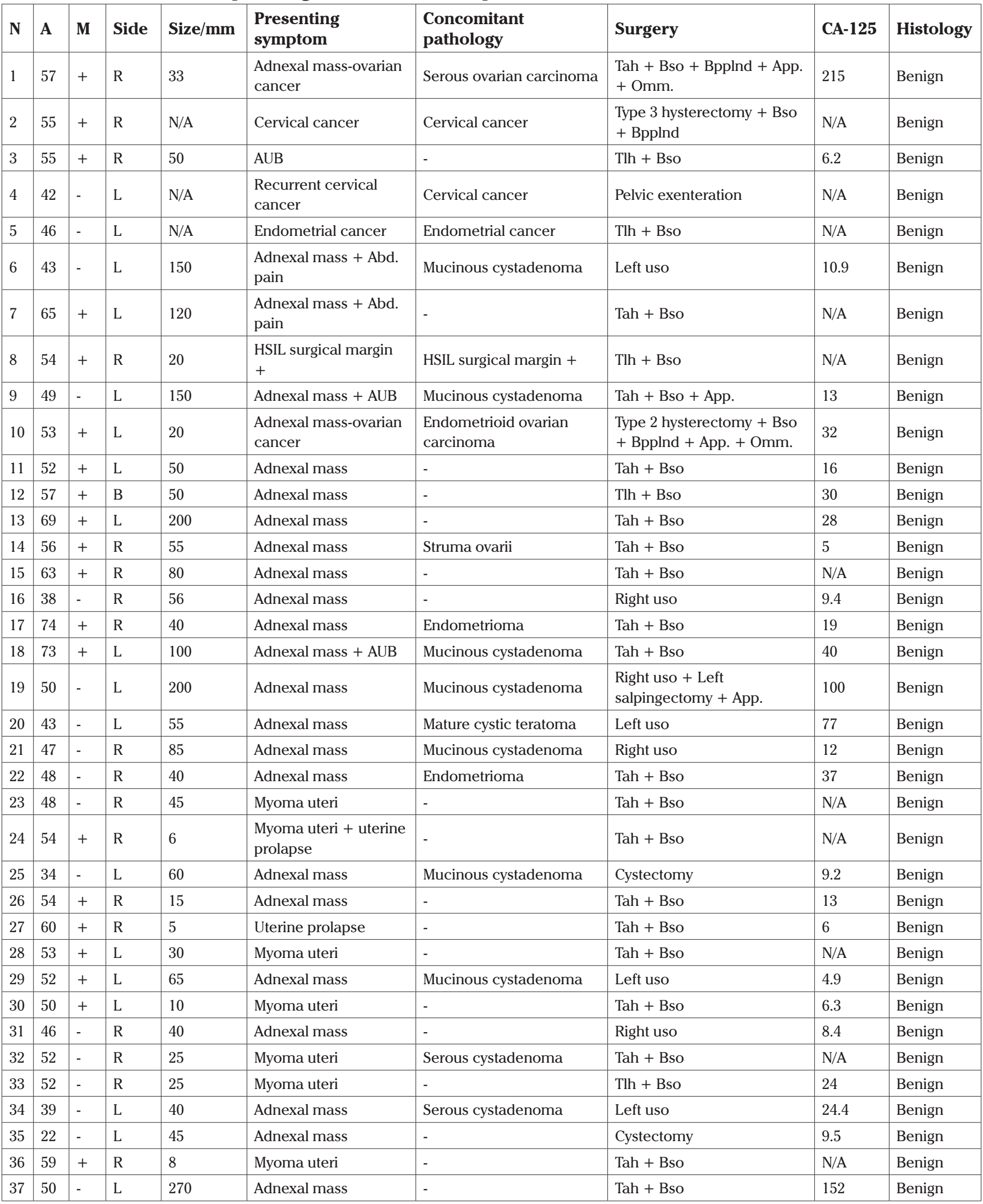


Table 1. Continued

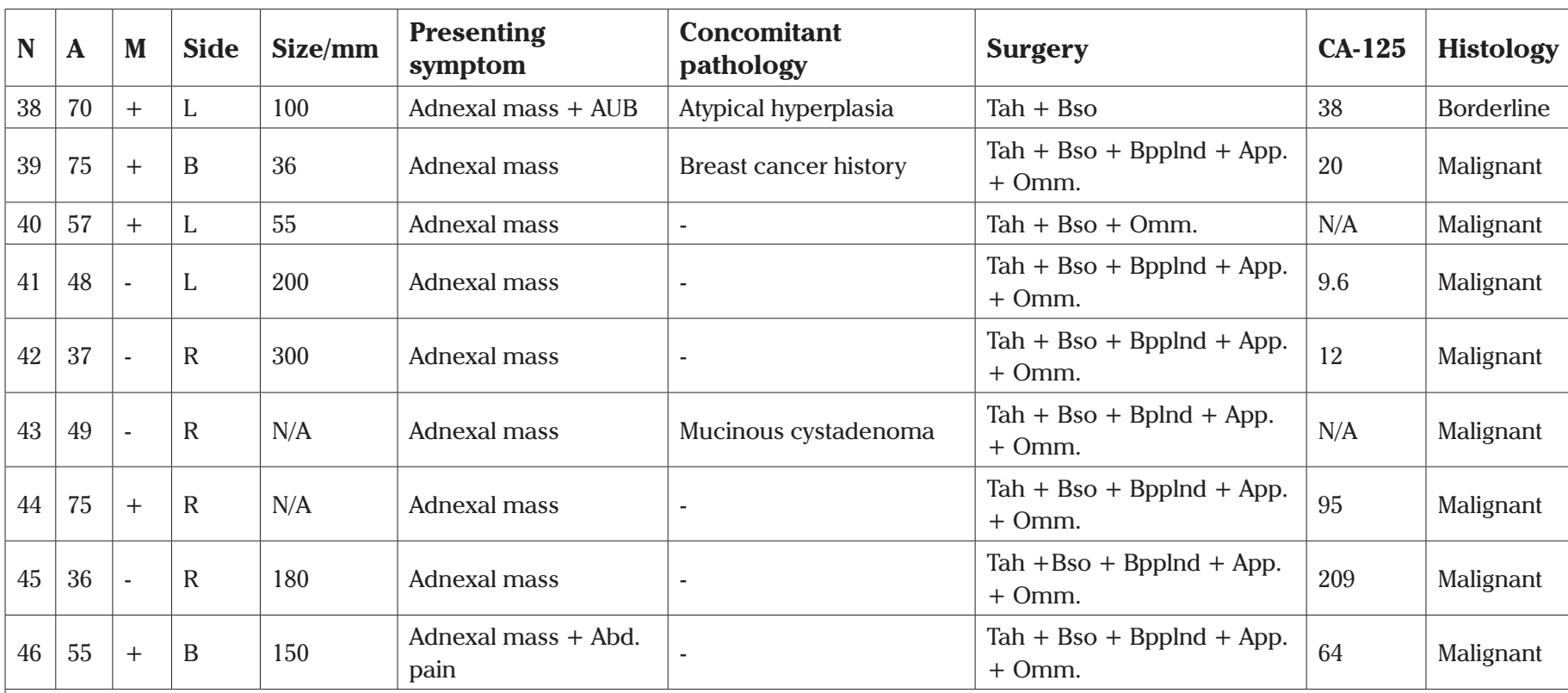

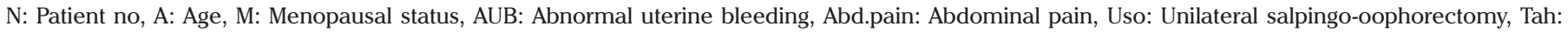

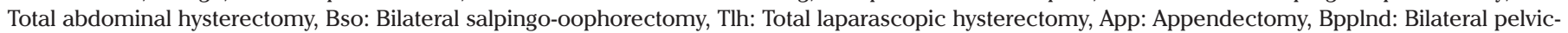
paraaortic lymph node dissection, HSIL: High grade squamous intraepithelial lesion, L: Left, R: Right

Table 2. The clinical and oncological characteristics of cases with malignant Brenner tumors

\begin{tabular}{|c|c|c|c|c|c|c|}
\hline Case no & Age & Stage & Chemotherapy & Recurrence (time/site/treatment) & Follow-up time (m) & Outcome \\
\hline 39 & 75 & IIIC & $\begin{array}{l}C+P T x \\
(6 \text { cyc. })\end{array}$ & No & $47 \mathrm{~m}$ & Ned/Alive \\
\hline 40 & 57 & IIA & $\begin{array}{l}C+P T x+R T \\
(7 \text { cyc. })\end{array}$ & No & $12 \mathrm{~m}$ & NA \\
\hline 41 & 48 & IA & - & No & $96 \mathrm{~m}$ & Ned/Alive \\
\hline 42 & 37 & ICl & $\begin{array}{l}\text { C + PTx } \\
(6 \text { cyc. })\end{array}$ & No & $115 \mathrm{~m}$ & Ned/Alive \\
\hline 43 & 49 & IIIC & $\begin{array}{l}\text { C + PTx } \\
(6 \text { cyc. })\end{array}$ & $\begin{array}{l}86 \mathrm{~m} \\
\text { (paraaortic }+ \text { pelvic lymph node and liver) } \\
\text { Surgery }+6 \text { cyc. } \mathrm{C}+\mathrm{PTx}\end{array}$ & $96 \mathrm{~m}$ & Ned/Alive \\
\hline 44 & 75 & IIIC & $\begin{array}{l}\text { C + PTx } \\
(6 \text { cyc. })\end{array}$ & No & $12 \mathrm{~m}$ & DOD \\
\hline 45 & 36 & IC3 & $\begin{array}{l}\text { C + PTx } \\
(6 \text { cyc. })\end{array}$ & No & $125 \mathrm{~m}$ & Ned/Alive \\
\hline 46 & 55 & IIIC & $\begin{array}{l}\text { Cis }+ \text { PTx } \\
(6 \text { сус. })\end{array}$ & $\begin{array}{l}13 \mathrm{~m} \\
\text { (pulmonary + liver + pelvic side) } \\
\text { BEP + pelvic RT }\end{array}$ & $\begin{array}{l}53 \mathrm{~m} \\
\text { Progressive disease }\end{array}$ & DOD \\
\hline
\end{tabular}

Cyc: Cycle, C: Carboplatin, PTx: Paclitaxel, Cis: Cisplatin, RT: Radiotherapy, BEP: Bleomycin + Etoposid + Cisplatin, Ned: No evidence of disease, DOD: Dead of Disease, NA: Not available, m: Month

In the current study, 10 cases were detected incidentally after surgery for other indications. In these cases, the size of the tumor varied from $5 \mathrm{~mm}$ to $45 \mathrm{~mm}$ (Table 1).

BTs can be accompanied by mucinous cystadenoma, serous cystadenoma, benign cystic teratoma, or struma ovarii in approximately $20 \%$ of cases (8). Similarly, in the current study, coexistence with benign ovarian tumors was detected in 13
(28\%) cases. Roma and Masand (9) reported that up to $27 \%$ of BTs were associated with mucinous tumors. The coexistence of struma ovarii and BT is rare. According to the current literature, only seven cases have been reported (10). The origin of the BT and the struma ovarii association may be the germ-cell, as described in various studies, or due to the metaplastic features of the BT $(10,11)$. 
BTs might be accompanied by other ovarian tumors and be associated with endometrial pathologies in 4-14\% of patients. The stromal component of the BT, resembling the theca cells of the ovary, produces estrogen, which may be related to estrogenrelated pathologies (3). In the current cohort, BTs were seen to coexist with atypical endometrial hyperplasia in one patient and endometrioid-type endometrial cancer in another.

Synchronous tumors of the female genital tract account for only $1-6 \%$ of all genital neoplasms (12). Similarly, in this study, one case was diagnosed incidentally in a case of serous ovarian carcinoma and one case in an endometrioid ovarian tumor. Coexistence with the endometrioid ovarian tumor and the history of breast cancer in one patient also supports estrogenrelated events. These findings also explain the vaginal bleeding complaint in these patients. Although no data exist about the coexistence of cervical cancer and BTs in the literature, two (4.3\%) patients had cervical cancer in the current study. This might have resulted from the fact that the study was conducted in a gynecological oncology clinic.

BTs are known to range from benign to malignant. In the current study, 1 patient had borderline and eight patients had MBT. Borderline BTs are rare and defined as "epithelial proliferation without stromal invasion" and only 60 cases have been published in the English literature to date (13). Most of the cases in the literature were reported as older than 50 years. Presenting with postmenopausal bleeding indicates that some of the borderline BTs may contain hormone-secreting elements. The case in the current study with borderline BT was 70 years old and the main complaint was postmenopausal bleeding. Histopathological examination showed concomitant atypical endometrial hyperplasia. Similar to the cases in literature, this finding indicates that endometrial hyperplasia may have developed due to the hormonal effects of borderline BT.

Whereas the vast majority of BTs are benign and often found incidentally, MBT, accounting for $<5 \%$ of all BTs, are extremely rare (5). The clinical and oncological features of the eight patients with MBT are summarized in Table 2. The median age of the MBT cases was 52 years, similar to the study of Han et al. (14). A small number of studies provide the only available information about the treatment of these patients, and the optimal adjuvant management remains unclear. Surgery is the main treatment, as in the case of other epithelial ovarian carcinomas. In the reported case series carboplatin and paclitaxel had been used for adjuvant chemotherapy, as in other epithelial ovarian tumors $(6,14)$. In the presented series, all patients, except one case (stage $1 \mathrm{~A})$, received paclitaxel-carboplatin as adjuvant therapy in line with previous reports. A recent large retrospective study reported the median tumor size as $10 \mathrm{~cm}$ for MBT and most of these were unilateral (15). In this case series, the median tumor size was $16.5 \mathrm{~cm}$ and the majority of the tumors (6/8) were unilateral.

Lymph node dissection is a controversial issue in MBT. Nasioudis et al. (15) reported that lymphatic spread and lymph node dissection did not confer any disease-specific survival (DSS) benefit to these patients. Approximately 50\% of patients with surgical tumor excision had concomitant lymph node dissection, but only $5 \%$ of these patients had evidence of lymphatic spread. In that study, no DFS difference was found between the lymphadenectomy group and nonlymphadenectomy group (15). In the current study, lymph node dissection was performed in all except two patients (stage 1A and IIA). No recurrence was observed in these early stage patients.

Complete chemotherapy response was obtained from $7 / 7$ patients who received carboplatin + paclitaxel chemotherapy in this series. Similarly, Gezginç et al. (6) reported a complete response rate in 9/10 patients, and the recurrence rate was $7 / 10$. These results support the importance of complete cytoreductive surgery before chemotherapy. In the current study recurrence was seen only in $2 / 8 \mathrm{MBT}$ patients. One of the patients with recurrence was given chemotherapy following surgery for recurrence, and that patient is currently alive without disease. The second patient, who had recurrence after primary adjuvant chemotherapy was given bleomycin, etoposide, and cisplatin. Palliative RT was given for progressive disease and the control of pelvic recurrence. The patient died from the disease in the $53^{\text {rd }}$ month. NCCN guidelines on epithelial ovarian cancers do not include RT as a primary treatment recommendation, but reference palliative RT for local symptom control (16).

Although specific tumor markers for MBT have not been identified, CA-125 can be used to monitor the effectiveness of therapy and to detect recurrence during follow-up (17). In the current study, 3/8 patients (38\%) had CA-125 levels $>35 \mathrm{IU} / \mathrm{mL}$. Roth et al. (18) reported that MBTs are associated with better survival compared to other epithelial ovarian tumors. In the current study, 4/8 patients were diagnosed at stage IIIC and the others were stage IA, IIA, IC1, and IC3. Two reported recurrences were seen at stage IIIC. In the early stages, no recurrence was observed. These findings support the suggestion that DSS is better in the early stages, in agreement with the findings of Nasioudis et al. (15).

This report presents a single-center experience over fifteen years. Due to the relatively low number of cases, the cohort provides information about benign, borderline, and malignant MBTs of the ovary. This study can be considered to provide valuable information in terms of oncological results about MBTs, as rare case reports and a limited number of case series in many reports are presented together. 


\section{Conclusion}

BTs are rare and mostly incidental findings. It should be remembered that these tumors can secrete hormones and can cause endometrial pathologies. Especially for malignant forms, multicenter studies are needed to be able to establish the optimal treatment regimen and surgery.

Ethics Committee Approval: This study was approved by the University of Health Sciences Turkey, Etlik Zübeyde Hanım Women's Health Care, Training and Research Hospital, approved the study (approval number: 90057706-799/8, date: 30.10.2019).

Informed Consent: Written informed consent was obtained from all patients on admission for medical information to be used anonymously for academic purposes.

Peer-review: Externally peer-reviewed.

Author Contributions: Surgical and Medical Practices: D.Y., T.T., N.B., S.K., F.K.; Concept: D.Y.; Design: D.Y., S.K.; Data Collection or Processing: D.Y., Ç.K., C.Ç., E.Ü.; Analysis or Interpretation: D.Y., G.K.C.; Literature Search: D.Y., Ç.K., C.Ç., E.Ü.; Writing: D.Y.

Conflict of Interest: No conflict of interest is declared by the authors.

Financial Disclosure: The authors declared that this study received no financial support.

\section{References}

1. Longacre TA, Gilks CB. Surface epithelial-stromal tumors of the ovary. Gynecologic Pathology. In: Nucci MR, Oliva E, Goldbum JR, (editors). London: Churchill Livingstone Elsevier; 2009. p. 393-444.

2. Speert H. Obstetrical-gynecological eponyms: Fritz Brenner and Brenner tumors of the ovary. Cancer 1956; 9: 217-21.

3. Sharma M, Khangar B, Mallya V, Khurana N, Gupta S. Coexisting brenner tumor and endometrial carcinoma. J Midlife Health 2017; 8: 89-91.
4. Gaur JH, Hassan MJ, Elahi AA, Khetrapal S, Khan S, Jetley S. Synchronous benign Brenner's tumor of ovary with leiomyoma and endometrial adenocarcinoma in a postmenopausal female. J Can Res Ther 2019; 15: 1418-20.

5. Kurman RJ, Carcangiu ML, Herrington CS, Young RH (edts). WHO classification of tumours of the female reproductive organs. IARC WHO Classification of Tumours, World Health Organization; 2014.

6. Gezginç K, Karatayli R, Yazici F, Acar A, Çelik Ç, Çapar M, et al. Malignant Brenner tumor of the ovary: analysis of 13 cases. Int $\mathrm{J}$ Clin Oncol 2012; 17: 324-29.

7. Green GE, Mortele KJ, Glickman JN, Benson CB. Brenner tumors of the ovary: sonografic and computed tomograpfic imaging features. J Ultrason Med 2006; 25: 1245-51.

8. Hwang CS, Lee CH, Lee SJ, Kim YG, Kim A, Park DY, et al. A peculiar case report of extraovarian Brenner tumor arising in the omentum. World J Surg Oncol 2017; 15: 72.

9. Roma AA, Masand RP. Different staining patterns of ovarian Brenner tumor and the associated mucinous tumor. Ann Diagn Pathol 2015; 19: 29-32.

10. Terada T, Tateoka K. Ovarian cystic tumor composed of Brenner tumor and struma ovarii. Int J Clin Exp Pathol 2012; 5: 274-7.

11. Yoshida M, Okabayashi C, Tachibana M, Minami R. Coexisting Brenner tumor and struma ovarii in the right ovary: case report and review of the literature. Pathol Int 2004; 54: 793-97.

12. Matlock DL, Salem FA, Charles EH, Save EW. Synchronous multiple primary neoplasms of the upper female genital tract. Gynecol Oncol 1982; 13: 271-7.

13. Zheng R, Heller DS. Borderline brenner tumor a review of the literature. Arch Pathol Lab Med 2019; 143: 1278-80.

14. Han JH, Kim DY, Lee SW, Park JY, Kim JH, Kim YM, et al. Intensive systemic chemotherapy is effective against recurrent malignant Brenner tumor of the ovary: An analysis of 10 cases within a single center. Taiwan J Obstet Gynecol 2015; 54: 178-82.

15. Nasioudis D, Sisti G, Holcomb K, Kannien T, Witkin S. Malignant brenner tumors of the ovary; a population based analysis. Gynecol Oncol 2016; 142: 44-9.

16. Morgan RJ Jr, Armstrong DK, Alvarez RD, Bakkum-Gamez JN, Behbakht K, Chen LM, et al. Ovarian cancer, version 1.2016, NCCN Clinical Practice Guidelines in Oncology. J Natl Compr Canc Netw 2016; 14: 1134-63.

17. Lang SM, Mills AM, Cantrel LA. Malignant brenner tumor of the ovary: rewiev and case report. Gynecol Oncol Rep 2017; 22: 26-31.

18. Roth LM, Gersell DJ, Ulbright TM. Ovarian brenner tumors and transitional cell carcinoma: recent developments. Int J Gynecol Pathol 1993; 12: 128-33. 